\title{
Prevalence of Contra Caecum Parasite Infestation of Nile Tilapia and African Catfish in Lake Ziway, Ethiopia
}

\author{
Nigussu Fasi ${ }^{1 *}$, Tsegaye Teshome, Dessie Sheferaw \\ Hawassa University, School of Veterinary Medicine and Agriculture, Ethiopia
}

"Corresponding author: Nigussu Fasil, Assistant Professor, Hawasssa university, School of Veterinary Medicine and Agriculture, Ethiopia. Tel: +251913304082; Email: fasilkedesegne@yahoo.com

Citation: Fasil N, Teshome T, Sheferaw D (2017) Prevalence of Contra Caecum Parasite Infestation of Nile Tilapia and African Catfish in Lake Ziway, Ethiopia. J Fish Aqua Dev: JFAD-120. DOI:10.29011/JFAD-120/100020

Received Date: 20 August, 2017; Accepted Date: 14 September, 2017; Published Date: 22 September, 2017

\begin{abstract}
A cross sectional study was conducted from November 2016 to March 2017 in Lake Ziway to determine the prevalence of contra caecum parasites infestation of African cat fish and Nile tilapia. A total of 412 randomly selected fish species comprising of 157 African catfish and 225 Nile tilapia were sampled. All the sampled fish were eviscerated in laboratory to investigate the larva of contra caecum parasites. Chi-square statistic, p-value and comparison of proportion were used to analyze the data. The overall prevalence of contra caecum parasites of fish was $12.62 \%(52 / 412)$. The distribution of parasite was highly significantly affected by fish species $(\mathrm{p}=0.000)$. However, the difference between sexes was not seemed to be statistically significant $(\mathrm{p}=0.234)$ despite the prevalence was slightly higher in female $(14.65 \%)$ than male $(10.75 \%)$ fish. The contecaecum parasite is zoonotic. Therefore, awareness creation activities and control of fish parasites should be conducted in the study Lake.
\end{abstract}

Keywords: Contra Caecum Parasite; Fish; Lake Ziway; Prevalence

\section{List Abbreviations:}

CSA : $\quad$ Central Statically Agency

FAO : Food and Agricultural Organization

\section{Introduction}

Fish is an important source of protein to humans and other animals. Fishing activities also offer employment opportunities to many people as well as income at household and national level. Therefore, it can provide numerous yields to a large number of unskilled people including women through their involvement in fish processing activities [1]. More than 200 species of fish are known to occur in lakes, rivers and reservoirs in Ethiopia [2]. The country depends on its inland water bodies for fish supply for its population. The annual fish production potential of the country based on empirical methods on individual lake surface area and mean depth of major water bodies was estimated to be 30.000 to 51.000 tons [3].

Lake Ziway serves as a home for several species of fish including Oreochromis niloticus, Tilapia zillii, Barbus species, Clar- ias gariepinus and Carp species, in which some are native and others are exotic. The exotic fish species were introduced into the Lake by the Ministry of Agriculture with the aim of fishery development [4]. The annual fish production potential yield of Lake Ziway was estimated between 3,000 to 6680 tons per year [5]. Freshwater fish can serve as definitive, intermediate or paratenic (Transport) hosts in the life cycles of many species of protozoan, metazoan and crustacean parasites. The parasites usually affect the marketability of commercially produced fish, thus raising a lot of public health concerns, especially in areas where raw or smoked fish are eaten [6].

Fish parasites are known to cause mortality both in aquaculture and inland fisheries and some are also a cause for human diseases in many areas of the world [7]. Disease and parasites infestation of aquaculture fish species in Africa have been poorly studied in Africa as a whole and in sub-Saharan Africa in particular (South Africa being the exception). So, parasites are the most prevalent problems in African fresh water [8]. Parasites of fish are of concern since they often produce a weakening of the hosts immune system thereby increasing their susceptibility to secondary infection by disease causing agents (e.g. fungi, bacteria and viruses) resulting in the nutritive devaluation of fish and subsequent economic losses [9]. In fish farming or aquaculture, for example, some parasites 
may be highly deleterious for fish species causing serious outbreaks of diseases and contribute to high fish mortalities resulting in economic losses [10]. parasites of fishes may cause a decrease in growth rate, weight loss, emaciation or even suppress reproductive activity [11].

Nematodes are common parasites in freshwater and marine fish, amphibians, reptiles and birds. Larval stages of nematodes either occur encysted in the tissue or free in the body cavity of fish, while the adults live in the stomach or small intestine of piscivorous birds, notably pelicans, cormorants, herons and darters [6]. Of all the larval nematodes, the most common genus is Contra caecum, which has a trans-African distribution and has been recorded in both Clarias gariepinus and Oreochromis niloticus fish species [12]. Adult Contra caecum species from fish-eating birds have been studied and recorded by Saayman et al. (1991) [13]. Contra caecum species are in genus ascaridoide, family anisakidae, and they are parasite of aquatic birds and mammals. The larvae of contra caecum species occur in the body cavity and mesenteries of fish while adult in gut of pscivorous birds, notably pelicans, cormorants, herons and darters [14].

So, the objective of this paper is

- To assess the prevalence of contraceacum parasite of African catfish and Nile tilapia of Lake Ziway,

- To identify the risk factors for parasitic infestation and

- To aware public about zoonotic importance of parasite when people eat raw fish meat.

\section{Material and Methods}

\section{Study Area}

The study was conducted on Lake Ziway which is adjacent to Batu town located in Oromia regional state, in eastern Shoa; Adami Tulu jiddo wereda at distance of $160 \mathrm{~km}$ from Addis Ababa. The town is adjacent to Lake Ziway (Lake Dambal) on western shore. The economy of town is based on fishing and horticulture. Lake Ziway is one of the fresh water rift valleys of Ethiopia. It is $31 \mathrm{~km}$ long and $20 \mathrm{~km}$ wide with surface of 440 kilometer square. It has maximum depth of $9 \mathrm{~m}$ and elevation of 1,636 meters above sea level. The climate of Ziway is warm and temperate. The summer has a good deal of rain fall, while the winter has very little rainfall. The average of annual temperature and rainfalls are $19.3^{\circ} \mathrm{c}$ and $837 \mathrm{~mm}$ respectively. The lake is fed primarily by two rivers, the Meki from the west and the Katar from the east direction. It contains five islands, including Debre Sina, Galila, Bird Island and Tulu Gudo [15].

\section{Study Population}

Ziway Lake is endowed by many native and exotic fish species. Of these, four species of fish are commercially important. These are African catfish, Nile tilapia, common carp and crussian carp [16]. The fish species included in the current study were Nile tilapia and African cat fish of the Lake Ziway. From commercially important fishes, the rest two were not included because they can resist the infestation of contra caecum parasite. The native fish species were not included except African cat fish and Nile tilapia because their body sizes were very small and hence, it was not convenient to catch them during study periods. In study both sexes and species of fishes were included.

\section{Study Design}

A cross sectional study was conducted from November 2016 to March 2017 at Lake Ziway to determine and identify the prevalent contra caecum parasite on randomly selected Nile tilapia and African catfish species.

\section{Sample Size and Sampling Method}

A simple random sampling method was used to select study fish species. The sample sizes needed for the study were calculated by using the formula given by Thru field (2005) [17].

$\mathrm{n}=\frac{1.96^{2} \mathrm{P}(1-\mathrm{P})}{\mathrm{d}^{2}}$

Where $\mathrm{n}=$ Total calculated sample size, $\mathrm{P}=$ expected prevalence, $\mathrm{d}=$ absolute precision.

The study considered expected prevalence of $50 \%$ for the sample size calculation, and hence, the sample sizes were 384 . But previously, the proportion of contra caecum infestation was stated in research conducted on prevalence of internal parasite and fish disease survey of Ziway Lake. Extra 28 species fishes were added for purpose of precision. So, overall 412 sample sizes were selected.

\section{Study Methodology}

All fish samples selected by lottery method were purchased from fish seller at near of Ziway Lake. Then, the samples were transported immediately in ice box to Ziway Fishery Research Center Laboratory. In the laboratory, the species, sex and site of infection of the fish were identified and recorded. The external surface of each organ was examined and postmortem examination was done using appropriate postmortem kits using standard evisceration technique [18]. In short, the whole body cavity was cut opened and examined for parasite. The internal organs were removed and placed separately in Petri dishes containing $0.75 \%$ saline solution. The collected parasite was preserved in 70\% ethanol and fixed in glycerin for further identification. Finally, the parasite was identified under stereo microscope using the identification guideline of Paperna (1996) [6].

\section{Data Management and Analysis}

Collected data were summarized as proportion by descriptive statistics. Then the data analyzed for the considered risk factors by 


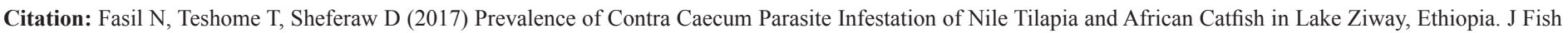
Aqua Dev: JFAD-120.

Chi-square test, 95\% CI and p-value. For the analysis STATA 11 software will be used. For all statistical analysis, a significant level (p-value) of less than 0.05 was considered as statistically significant.

\section{Result}

In this study a total of 412 fish samples were selected. Of these, 52 were affected by contra caecum parasite, giving the overall prevalence of $12.62 \%$. Out of the examined 255 Nile tilapia, $19(7.45 \%)$ were affected by the parasite. However, from the examined 157 African cat fish, 33 (21.01\%) were affected by the parasite. The result reveal that there was statistically significant difference $(\chi 2=16.2208, p=0.000)$ in the distribution of parasite between the two species of fish. African cat fish was found $(p=0.000, C I=0.146065-0.2743172)$ more association with contra caecum parasite than Nile tilapia (Table 1).

\begin{tabular}{|c|c|c|c|c|c|}
\hline Variables & $\begin{array}{c}\text { No of } \\
\text { fish ex- } \\
\text { amined }\end{array}$ & $\begin{array}{l}\text { No of fish } \\
\text { affected }\end{array}$ & $\begin{array}{c}95 \% \\
\text { CI }\end{array}$ & $X 2$ & P-value \\
\hline \multicolumn{6}{|l|}{ Fish species } \\
\hline Nile tilapia & 255 & $19(7.45 \%)$ & $\begin{array}{c}0.042- \\
0.16\end{array}$ & 16.221 & 0.000 \\
\hline $\begin{array}{c}\text { African } \\
\text { catfish }\end{array}$ & 157 & $33(21.01)$ & $\begin{array}{c}0.146- \\
0.24\end{array}$ & & \\
\hline Total & 412 & $52(12.62 \%)$ & - & - & - \\
\hline
\end{tabular}

Table 1: The Association of Fish species to the prevalence of contra caecum parasite at Lake Ziway.

(Table 2) Depicts the occurrence of contra caecum parasites in male and female fish. Out of the examined 214 male fish, $23(10.75 \%)$ were infected by contra caecum parasite. On the other hand, of the examined 198 female fish, 29(14.65\%) were affected by contra caecum parasite of fish. The occurrence of the internal parasites did not show any statistical significant difference between male and female fish $(\chi 2=1.4175, \mathrm{p}=0.234)$.

\begin{tabular}{|c|c|c|c|c|c|}
\hline $\begin{array}{c}\text { Vari- } \\
\text { ables }\end{array}$ & $\begin{array}{c}\text { No of fish } \\
\text { examined }\end{array}$ & $\begin{array}{c}\text { No of fish } \\
\text { affected }\end{array}$ & $\mathbf{9 5 \%}$ CI & $\boldsymbol{X 2}$ & P-value \\
\hline Sex & & & & & \\
\hline Female & 198 & $29(14.65 \%)$ & $\begin{array}{c}0.969- \\
0.196\end{array}$ & 1.4175 & 0.234 \\
\hline Male & 214 & $23(10.75 \%)$ & $\begin{array}{c}0.066- \\
0.149\end{array}$ & & \\
\hline Total & 412 & $52(12.62 \%)$ & - & - & - \\
\hline
\end{tabular}

Table 2: The Association of sex of Fish to the prevalence of contra caecum parasite at Lake Ziway

The genus Contra caecum was the parasite affecting both species and sexes of fish in Lake Ziway. The larva of parasite was observed in pericardium cavity $(13.46 \%)$, intestine $(11.54 \%)$, ovary
$(17.3 \%)$ and caecum $(17.3 \%)$. The larva of parasite also observed on mesentery (13.46\%), liver (15.38\%) and heart (11.54\%).

\section{Discussion}

The study of this work revealed that Nile Tilapia and African cat fish were infested by contra caecum parasite. Prevalence of parasite was higher in African cat fish $(21.01 \%)$ than Nile tilapia $(7.45 \%)$. It was due to feeding behavior of African catfish. In fact, the African catfish is less selective or omnivorous feeding behavior [19]. This behavior of the fish could expose it for easy transmission of parasites from invertebrate intermediate hosts and fish intermediate hosts [20].

The prevalence of contra caecum parasite of Nile tilapia in current study was lower than prevalence previously reported in Lake Alau (23.8\%) in Nigeria [21], 39.9\% in northern Tana [22], in Lake Naivasha $85 \%$ with mean of 9 worms per fish, in Lake Baringo 70\% with 5 worms per fish and in Lake Magadi $80 \%$ with a mean of 2 worms per fish were reported [23], in southern gulf of Lake Tana (59.77\%) in Ethiopia [24] and 39.67\% at Lake Awassa [25]. Teferra (1990) [26] on the other hand reported that, in Lake Tana $68.66 \%$ Oreochromis niloticus were found infested with larval nematode Contra caecum species. This difference might be due to the geographical variation difference offering suitable ecological niches for the parasite. As described by Paperna (1996) [6], the present of intermediate hosts and prevailing physiochemical factors will affect parasitic diseases. Moreover, the hygienic conditions and the prevailing climatologically factors may affect the distribution of parasites. However, the prevalence parasite infestation of Nile tilapia obtained in the current study was almost nearly similar to the prevalence of $8.60 \%$ recorded in the previous study in the same Lake two years ago.

The prevalence of contra caecum parasite of Africa cat fish was also lower than the previous report of $27.60 \%$ at Lake Awassa in Ethiopia [27] and at lake Lake Chivero (42.6\%), Zimbabwe [10]. It was also lower than prevalence recorded from the Hartbeespoort dam (95.3\%) by Boomers (1982) and recorded a prevalence of $46 \%$ from Lake St. Lucia [12]. Current prevalence of contra caecum infestation of African catfish was higher than previous report from the same lake (5.33\%) in Ethiopia [28]. This increased value due to gutting activity conducted at side of Ziway Lake that perpetuate the life cycle of contra caecum parasite. Everything except edible fish was returned to the lake. Fish butchers wash their hands and materials within lake. They also expose gutted internal organs to surround birds. But the prevalence parasite infestation of African catfish obtained in the current study was almost nearly similar to the prevalence of $19.02 \%$ recorded in the previous study in the same Lake two years ago.

In current study Even though statistically no significant difference obtained relatively higher prevalence of larvae of Contra caecum nematode infestation was recorded in female $(14.65 \%)$ than male $(10.75 \%)$. This observation correspond to the findings of 


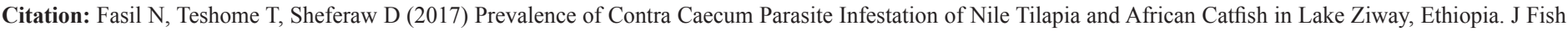
Aqua Dev: JFAD-120.

Imam and Dewu (2010) [29], Bichi and Ibrahim (2009) [30] and Mhaisen et al. (1988) [31], It was due to female fish were generally more liable than male to infestation with nematodes, cestodes, acanthocephalan, crustacean and copepod parasites [32]. The difference in infestation rate of male and female fish recorded in these studies could be attributed to genetic predisposition and differential susceptibility owing to the difference of their physiological condition. Female fish especially gravid ones are susceptible to helminthes infestation as this physiological state could reduce the resistance of the fish to infestation by the parasite $[33,34]$.

\section{Conclusion and Recommendations}

The study of this work revealed that Nile Tilapia and African cat fish were infested by contra caecum parasite. Prevalence of parasite was higher in African cat fish than Nile tilapia. The parasite has many hosts range including some aquatic fish, and piscivorous birds. So, infestation of fishes by this Parasite can cause nutritive devaluation of fish and subsequent economic losses.

Gutting activity conducted at side of Ziway Lake was one of the factors that perpetuate the life cycle of contra caecum parasite. Everything except edible fish was returned to the lake. Fish butchers wash their hands and materials within lake. They also expose gutted internal organs to surround birds. The parasite has also zoonotic importance which human can be affected by eating raw fish meat. Based on above conclusion the following recommendations are forwarded:

- Constructing fish abattoir is essential. It has numerous advantages such as: - To create job opportunity for people, suitable for tax collection, comfortable for regulation and to alleviate over fishing activity.

- Appropriate disposal of gutted organs is essential in order not expose to surrounding birds.

- $\quad$ Price gain between fish butchers and fish sellers should be balanced. Fish sellers of ziway town were gain more price than fish butchers. For this reason, fish butchers were spending most of time on gutting and most of them ate a raw fish meat.

- Creating public awareness about zoonotic importance of contra caecum parasite is essential in order human not to consume raw fish meat without cooking.

\section{References}

1. FAO (2003) Information on fisheries management in federal republic of Ethiopia.
2. Jerbe $T$ (2007) Fish diversity in the main drainage systems of Ethiopia.

3. FAO (2003) Strategies of increasing the sustainable contribution of small-scale fisheries for food security.

4. Abera L, Getahun A, Lemma B (2014) Composition of commercially important fish species and some perspectives into the biology of the African Catfish (Clarias gariepinus), Lake Ziway, Ethiopia. International Journal of Advance Research 2: 864-871.

5. Yohannes F (2003) Management of Lake Ziway fisheries in Ethiopia.

6. Paperna I (1996) Parasites, infections and diseases of fish in Africa. An update FAO/CIFA Technical Paper 31: 157-170.

7. Robert L, Janovy J (2000) Gerald D. Schmidt and Larry S. Roberts Foundations of Parasitology, 6th edition.

8. Hecht T, Endermann F (2007) The impact of parasites, infections and diseases on the development of aquaculture in Sub-Saharan Africa. Journal of Applied Ichthyology 14: 3.

9. Onyedineke N, Obi U, Ofoegbu P, Ukogo I (2010) Helminth parasites of some freshwater fish from river Attlushin, Edo State, Nigeria. Journal of America science 6: 16-21.

10. Barson M (2004) The occurrence of Contra Caecum Larvae species in the catfish (Clarias gariepinus) from Lake Chivero, Zimbabwe. Onderstepoort Journal of Veterinary Research 71: 35-39.

11. Chandra K (2006) Fish parasitological studies in Bangladesh: A Review on Journal of Agricultural and Rural Development 4: 9-18.

12. Whitfield A, Heeg J (1977) On the life cycles of the cestode Ptychobothrium belones and nematodes of the genus Contra caecum from Lake St. Lucia, Zululand. South African Journal of Science 73: 121-122.

13. Saayman J, Mashego S, Mokgalong N (1991) Parasites of the fish population with notes on the helminth parasites of the water birds of Middle Letaba Dam.

14. Anderson R (2000) Nematode Parasites of Vertebrates, their Development and Transmission.

15. CSA (2008) Federal Democratic Republic of Ethiopia central Stastical agency Information on Fisheries Management, climate and geographical location of Ziway town.

16. Eshetu $Y(2000)$ Preliminary survey of parasites and bacterial pathogens of fish at Lake Ziway. SINET: Ethiopia Journal science 23: 2533.

17. Thrusfield M (2005) Veterinary Epidemiology. Blackwell Science Ltd Singapore. 